\title{
LA HERENCIA ACÚSTICA PARA EL PORVENIR. UN LEGADO QUE DESAPARECE EN LA ERA DE LA INFORMACIÓN
}

\author{
Perla Olivia Rodríguez*
}

...the question of the archive is not $[. .$.$] a question of the past.$ It is not the question of a concept dealing with the past that might already be at our disposal or not at our disposal, an archivable concept of the archive. It is a question of the future itself, the question of a response, of a promise and of a responsibility for tomorrow.

Jacques Derrida, Archive Fever: 36

\section{Resumen}

Este artículo analiza la situación de los archivos sonoros en la era de la información, periodo histórico que se caracteriza por la creación, distribución, intercambio y almacenamiento de grandes cantidades de información digital. En la era de la información, la digitalización se ha erigido como el único proceso a través del cual se pueden conservar, a largo plazo, los contenidos de los documentos sonoros grabados - desde hace más de un siglo y medio-, en diversos soportes analógicos. De forma paradójica, es en esta época donde esta herencia sonora corre el riesgo de desaparecer, con lo cual se perdería gran parte de la herencia acústica de la historia contemporánea grabada en sonidos.

Palabras clave: archivo sonoro, documento sonoro, era de la información.

\footnotetext{
* Instituto de Investigaciones Bibliotecológicas y de la Información, UNAM.
} 


\section{Abstract}

This paper analyzes the situation of sound archives in the information age, period characterized by the creation, distribution, exchange and storage of large amounts of digital information. During information age, digitalization has emerged as the only process whereby the contents recorded in analog supports -for more than a century and a half-, can be preserved for long term. Paradoxically, in this time the sound heritage is at risk of vanishing, thereby be lost much of the sound heritage of contemporary history recorded sounds.

Keywords: sound archive, sound document, information age.

\section{Introducción}

Registrar, atesorar y transmitir la memoria son acciones que animan a todas las sociedades; la acumulación y conservación de documentos a lo largo de la historia ha dado origen a la creación de los archivos. El archivo o arkheîon representa la pasión por conservar todo, registrar cada detalle y evitar que se pierda con el tiempo.

Derrida asocia el vocablo arché, que significa "comienzo" y "mandato", con el sentido de origen, lugar y poder que tiene el archivo. El arkheîon en griego significa "la casa", "el domicilio", "la residencia de los arcontes", en quienes residía el poder de guardar, proteger e interpretar los archivos. ${ }^{2}$

El archivo no es memoria viva o anamnesis, sino ubicación; a eso se debe que el poder político de los arcontes tenga tanta importancia en la definición de archivo. En éste -lugar de la memoria y el saber que detenta el poder-, coexisten, de acuerdo con Derrida, la pasión por conservar y la pulsión de muerte, es decir, la agresión y la destrucción del archivo; esto es lo que él denomina "mal de archivo". 3

El mal de archivo, o pulsión de muerte, constituye la reflexión con la que se inicia este artículo, el cual analiza la situación de los archivos sonoros en la era de la información, caracterizada, paradójicamente, por la

1 Derrida, Jacques, Archive Fever..., p. 1.

2 Ibid., p. 2.

3 Ibid., p. 12. 
proliferación de información en diversos formatos y lenguajes y por la pérdida inminente de la herencia acústica, que representa la memoria inmaterial y el saber acumulado durante más de 150 años.

Para abordar la compleja y desafiante situación de los archivos sonoros en el porvenir, se partirá de los orígenes de la grabación de los documentos sonoros exponiendo sus rasgos más significativos, continuando con la evolución de los archivos sonoros, la situación en la que se encuentran, y su porvenir como herencia acústica en la era digital.

\section{Los orígenes de la grabación de documentos sonoros}

A finales del siglo XIX surgió una nueva variante tecnológica para preservar la memoria: la grabación sonora. ${ }^{4} \mathrm{El}$ primer registro sonoro se grabó en 1860 y la primera fonoteca se fundó en 1899.

Édouard Léon Scott, Charles Cros y Thomas Alva Edison fueron los hombres que -con visiones diferentes en torno a la grabación sonora-, imaginaron, experimentaron y crearon tecnologías para fijar el sonido. En 1860, Édouard Léon Scott grabó Au clare de la lune en el fonoautógrafo que él mismo inventó. Durante más de un siglo esta grabación fue prácticamente olvidada, pues no era posible reproducirla y volver a escucharla. En 2008 un grupo de investigadores del Laboratorio First Sound, de la Universidad de Berkeley, logró que los sonidos grabados por Scott volvieran a oírse.

De acuerdo con Sarmiento, ${ }^{5}$ el poeta Charles Cros imaginó la primera caja portátil para congelar la palabra y en 1877 presentó en la Academia de Ciencias de Francia el documento "Procedimiento para grabar y reproducir fenómenos percibidos por el oído”; además, propuso la creación del paleófono. ${ }^{6}$ Pero antes de que Cros pudiera mostrar públicamente el prototipo de su trabajo, Thomas A. Edison inventó y presentó el fonógrafo, la tecnología capaz de grabar y reproducir sonidos; el fonógrafo fue -en un principio- un "aparato bastante rudimentario [...] que iría mejorando a lo largo de los años".

4 Edmondson, Ray, Filosofía y principios..., p. 25.

5 Sarmiento, José Antonio, La música del vinilo, p. 40.

6 Véase Notari, Matteo, La memoria del suono.

7 Sarmiento, op. cit., p. 9. 
El fonógrafo captó el interés y fue objeto del escrutinio público. Se trataba de una nueva tecnología que prometía mejorías en relación con la escritura y el libro. Sarmiento ${ }^{8}$ recupera el texto "El fonógrafo y su futuro", escrito por Edison en 1878, el cual destaca que las ventajas de "la innovación sobre los lentos, tediosos y costosos métodos actuales, son demasiado numerosas y son tan evidentes". El fonógrafo ofrecería a los directores de las firmas comerciales la posibilidad de prescindir de las cartas escritas, sin dictarlas en la casa o en la oficina, sin necesidad de un estenógrafo; para los impresores significaría una aportación que permitiría usar los oídos en lugar de los ojos; los testigos en juicios podrían hablar al fonógrafo para registrar su testimonio.

Edison reconoció que, si bien los libros pueden ser leídos por el lector profesional, el registro sonoro

"de un determinado libro, puede ser usado en los asilos para ciegos, hospitales, habitaciones de enfermos, o incluso con gran provecho y diversión, por la dama o el caballero cuyos ojos y manos pueden ser empleados de otra forma; o de nuevo, por el mayor placer que se puede obtener de un libro cuando es leído por un recitador que cuando es leído por un lector normal".?

El fonógrafo fue considerado como una innovación tecnológica atractiva y prometedora, que tendría varios usos. Edison vaticinó que el fonógrafo podría tener usos educativos; por ejemplo, grabando música, como archivo familiar, preservando la voz de un miembro de la familia; en la creación de audiolibros, juguetes, cajas de música y relojes fonográficos; como medio publicitario para anunciar el almuerzo; y para la grabación de discursos y declaraciones de personajes de la política. Más aún, expuso: “el fonógrafo perfeccionará el teléfono y revolucionará los presentes sistemas de telegrafía". ${ }^{10}$

Más allá de las predicciones de la nueva tecnología capaz de grabar los sonidos, el fonógrafo se empleó a finales del siglo XIX en el desarrollo de investigaciones de disciplinas como la dialectología, la etnolingüística, la etnomusicología y

8 Ibid., p. 48.

9 Edison, Thomas Alva, "El fonógrafo y su futuro", en Sarmiento, op. cit., p. 48.

10 Ibid., p. 50. 
la antropología. La acumulación de grabaciones sonoras propició la creación de nuevas instituciones de la memoria: los archivos sonoros o fonotecas. La primera fonoteca que se creó en el mundo fue la Phonogrammarchiv, de la Academia de Ciencias y Artes de Viena, fundada en 1899. ${ }^{11}$

A partir de entonces una parte de las ideas, creaciones y expresiones de la humanidad ha sido resguardada en archivos de investigación en las universidades, bibliotecas, emisoras de radio, centros de documentación, archivos nacionales de imagen y sonido y fonotecas privadas, entre otros tipos de instituciones que han tenido como misión principal la salvaguarda de la herencia acústica. Otra parte de las grabaciones sonoras se resguarda en colecciones de particulares que han dedicado buena parte de su vida a la recuperación y resguardo de sonidos grabados.

\section{Evolución de los archivos sonoros}

Las colecciones sonoras son recientes si se comparan con los documentos que se resguardan en las bibliotecas y los museos; en los primeros años del siglo xx comenzaron a emerger a nivel mundial los primeros archivos sonoros y audiovisuales. Algunas universidades europeas formaron fonotecas de investigación, entre las que destacan la Phonogrammarchiv, de Berlin, creada en 1900 en el Instituto de Psicología de la Universidad de Berlín; la fundada por la Sociedad de Antropología de París, en 1900; las instauradas en 1908 en la Universidad de Zürich y en San Petersburgo; ${ }^{12}$ y el Archivo de la Palabra, impulsado por el profesor Ferdinand Brunot en la Sorbona de París, en 1911. ${ }^{13}$

La creación de archivos sonoros de alcance nacional inició con la fundación de la Discoteca dil Stato d'Italia, creada en 1928 como una institución pública con fondos del Estado, con el propósito de recopilar la producción fonográfica italiana. ${ }^{14}$ En 1938 se creó la Fonoteca Nacional de Francia, adscrita a la Biblioteca Nacional de ese país.

11 Véase Edmondson, op. cit., p. 30; Schüller, Audiovisual Research..., p. 4; y Klijin y De Lusenet, Tracking The Reel World...

12 Klijin y De Lusenet, op. cit., p. 24.

13 Salmon, André, “SSe acabaron los libros, llegó la hora de los discos!”, en Sarmiento, op. cit., p. 82.

14 Véase Rodríguez Reséndiz, El archivo sonoro. Fundamentos para la creación... 
En la tercera década del siglo xx surgió otro tipo de archivos sonoros: los radiofónicos; el primero de ellos en 1931, en el seno de la British Broadcasting Company (BBC) de Londres. ${ }^{15}$ A partir de entonces, los archivos de las radiodifusoras crearon, almacenaron y difundieron una parte fundamental de la historia contemporánea.

Durante el siglo pasado los archivos sonoros y audiovisuales tuvieron caminos separados dado que se crearon filmotecas y archivos sonoros independientes. Sólo en dos instituciones convivieron -en un mismo archivo- la imagen fija (foto), la imagen en movimiento (películas) y las grabaciones sonoras: Central Photo, Sound and Film Archive de la Unión de Repúblicas Socialistas Soviéticas (URSS), fundado en 1934; y el National Film and Sound Archive de Australia, fundado en $1935 .^{16}$

A mediados del siglo xx, finalizada la Segunda Guerra Mundial, se crearon más institutos nacionales de audio y cinematografía ${ }^{17}$ y surgieron con ímpetu algunos de los principales archivos sonoros del mundo, como el National Sound Archive de Reino Unido, creado en 1955.

En las últimas décadas se observa la tendencia a incorporar documentos sonoros y audiovisuales en un mismo archivo, ${ }^{18}$ dando lugar a la edificación de grandes archivos nacionales de imagen y sonido, como el Swedish National Archive of Recorded Sound and Moving Images (1979), el Nederlands Instituut voor Beeld en Geluid (1997) y el National Screen and Sound Archive of W ales (2001), entre otros archivos. ${ }^{19}$ Esta orientación coincidió con el advenimiento y desarrollo de las tecnologías de la información aplicada en los procesos de preservación digital de documentos grabados en diversos soportes.

La historia de los archivos sonoros como instituciones de la memoria acústica de nuestros pueblos es reciente; a partir de 1980 la UNESCO reconoció como parte de la memoria de la humanidad todos los documentos audiovisuales, entre los que se incluyen los sonoros.

En consecuencia, los archivos sonoros pueden ser comprendidos como los lugares del saber y de la memoria, donde convergen la pasión por

15 Rooks, Simon, "What Happened to the BBC Sound Archive?", en Journal of the Society of Archivists, p. 177.

16 Véase Rodríguez Reséndiz, op. cit.

17 Klijin y De Lusenet, op. cit., p. 25.

18 Idem.

19 Ibid., p. 26. 
conservar y la pulsión de muerte, porque durante muchos años -gracias a los archivistas y documentalistas-, sólo una parte de los documentos sonoros se resguardó; miles de documentos sonoros se han borrado, destruido o tirado a la basura, e incluso se han regrabado por error, falta de sensibilidad, conocimiento o recursos económicos.

El documento sonoro es una fuente de información, un testimonio que da cuenta de la historia, la cultura y la creación artística, y un bien cultural que ha sido reconocido como parte del patrimonio intangible de la humanidad.

Por lo anterior se puede afirmar que la visibilidad y la importancia de las grabaciones acústicas, como recursos de información, vehículos de educación y cultura, son recientes y coinciden con el advenimiento de la era de la información digital.

\section{La transferencia de contenidos, una opción ante la pérdida}

Ante la irreparable pérdida de la herencia acústica -la pulsión de muerte de los archivos sonoros-, desde hace más de dos décadas la digitalización fue considerada como el proceso a través del cual se transferirían los contenidos de los documentos que habían sido grabados en soportes como cilindros, discos, casetes, cintas de carrete abierto, entre otros, a plataformas digitales, por lo que el paradigma de la preservación de los soportes originales en los archivos sonoros cambió. ${ }^{20}$ Los responsables de los archivos sonoros reconocieron que conservar los materiales originales era un esfuerzo vano, porque aun cuando se apliquen los procesos documentales existe el riesgo de pérdida, debido a la inestabilidad y fragilidad de los soportes analógicos y a la obsolescencia de los equipos de grabación y reproducción sonora. En consecuencia, la estrategia fue conservar, a través de la digitalización, los contenidos grabados en diversos soportes sonoros.

La digitalización de los archivos sonoros se tornó un proceso tecnológico de interés y preocupación para la comunidad archivística: desde los inicios de la década de los noventa muchos archivistas, documentalistas y responsables de los archivos sonoros habían utilizado el CD (disco compacto) y el DVD

20 Schüller, op. cit., p. 6. 
(disco digital versátil) como soportes de almacenamiento para conservar sus colecciones $;{ }^{21}$ ocuparon formatos de compresión como el MP3; omitiendo incorporar metadatos; además, la digitalización se procesó en cualquier equipo que estuviera al alcance. Cabe mencionar que el bajo costo de los nuevos soportes digitales contribuyó a esta práctica. Sin embargo, la era digital había llegado a los archivos sonoros y, con ello, nuevas expectativas de preservación.

Casi de forma simultánea a este entusiasmo por tener una copia digital de los documentos sonoros, a partir del año 2000, científicos, expertos, archivistas y documentalistas comenzaron a tomar una actitud crítica en relación con el uso de los discos compactos como soportes de almacenamiento. "Las dudas acerca de la confiabilidad de los CD y los DVD como medios para grabar se vieron reforzadas por el aumento en los reportes de fallas en los discos durante el proceso de manufactura". ${ }^{22}$ Incluso, se consideró que los CD y los DVD eran los más inestables y frágiles soportes de grabación sonora que han existido -motivo por el cual no se recomiendan como soportes de almacenamiento-. Kevin Bradley advirtió que, si se consideran el decaimiento y la obsolescencia del soporte, se requerirá que los contenidos sean migrados a otro formato. Los CD sólo pueden utilizarse de forma temporal, siempre y cuando se sigan ciertos lineamientos y estándares durante la digitalización; por ello, la Asociación Internacional de Archivos Sonoros y Audiovisuales (IASA) editó, en 2001, las Normas, prácticas recomendadas y estrategias IASA TC 03, con una serie de orientaciones y recomendaciones, ante la presencia y cada vez mayor utilización de la tecnología digital en los archivos sonoros. Esta publicación fue una primera guía que ayudó y orientó los proyectos iniciales de digitalización de los archivos sonoros.

En la actualidad, la digitalización es una tarea necesaria en todo archivo sonoro que desee conservar y dar acceso a largo plazo a sus colecciones de sonido. Es el elemento que vincula al archivo tradicional, que conserva soportes analógicos, con el nuevo archivo digital sonoro; más aún, es el proceso tecnológico que dio inicio a la preservación digital.

21 Rodríguez Reséndiz, op. cit., p. 153.

22 Bradley, Kevin, Riesgos asociados con el uso de los discos compactos..., p. 9. 